\title{
Placental ferritin in coeliac disease: relation to clinical stage, origin, and possible role in the pathogenesis of malignancy
}

\author{
G Dinari, I Zahavi, H Marcus, C Moroz
}

\begin{abstract}
Placental ferritin is a tumour associated antigen present in the serum of patients with active Hodgkin's and non-Hodgkin's lymphoma, and the serum values fall during remission of the disease. There is no correlation between placental and total blood ferritin values. Because of the strong association between coeliac disease and lymphoma, 19 children with active and 25 with inactive coeliac disease were screened for the presence of placental ferritin. Thirty two children with other intestinal disorders served as controls. Placental ferritin was identified by using a monoclonal antibody in an ELISA procedure. The mean (SEM) placental ferritin value in the control serum was $12.6(2.4)$ while the values in serum of patients with active and inactive coeliac disease were $117(22.8)$ and $43.8(10.2)$ $\mathrm{U} / \mathrm{ml}$ respectively. Patients with active coeliac disease differed significantly from both control subjects $(p=0.0004)$ and those with inactive disease $(p=0.03)$. Peripheral blood lymphocytes contained no placental ferritin. It was present, however, in lamina propria lymphocytes of intestinal biopsy specimens from active coeliacs. Placental ferritin was also found in some of the better differentiated malignant cells in two patients with adult onset enteropathy associated lymphoma. Placental ferritin is known to have an immunosuppressive effect, and this may be one of the necessary steps in the development of malignancy associated with coeliac disease. Gluten free diet, by reversing this state, may have a role in the prevention of lymphoma.
\end{abstract}

The association between coeliac disease and malignancy has been recognised for many years. ${ }^{1}$ Over half of the malignancies are lymphomas, and it has become clear that patients with coeliac disease have a 50 to 100 fold greater risk of developing malignant lymphoma than the general population. ${ }^{2-}$ Lymphoma may cause deterioration of well controlled coeliac disease or present simultaneously with this disorder. The symptoms of coeliac disease and lymphoma are very similar initially, often resulting in late diagnosis and poor prognosis. ${ }^{+5}$ The exact risk of developing malignancy in coeliac disease is unknown, partly because the precise prevalence and incidence of the disease in the general population is unknown. ${ }^{+6}$

Ferritin is a widely distributed iron storage protein, and multiple molecular forms of ferritin have been isolated from various tissues. Using monoclonal antibodies, Moroz et al were able to show a specific placental ferritin isoform. ${ }^{7}$ It was found that placental ferritin was not detected in most healthy adult blood donors but it was raised in the sera of patients with lymphoproliferative disorders. ${ }^{7}$

In a preliminary communication, ${ }^{8}$ we reported that serum placental ferritin values are increased in active coeliac disease, and decrease after initiation of a gluten free diet. The purpose of this study was to expand the number of patients studied, to identify the cellular origin of placental ferritin, and to formulate a hypothesis on its role in the development of lymphoma in coeliac disease patients.

\section{Patients and methods}

PATIENTS

Sera from 19 children with active coeliac disease and 25 children with the disease in remission were screened. The diagnosis of coeliac disease was made according to the European Society for Paediatric Gastroenterology and Nutrition criteria. ${ }^{9}$ Thirty two children with irritable bowel, abdominal pain, or constipation served as control subjects. Sera from children with active disease were collected either at the time of initial diagnosis or during a period of gluten challenge, when they were shown to have subtotal villous atrophy. Sera from children with inactive coeliac disease were collected after at least one year on a gluten free diet. Gluten free diet was shown to cause morphological recovery in all patients, and in eight children the biopsy specimens showing recovery were taken within three months of the placental ferritin determination. All tests were done on blood samples taken during routine clinical evaluation of the patients or from our sera bank. The mean (SEM) age of the control subjects was $9(0.9)$ years (median 8 , range 2-18 years); that of the children with active disease was $9.9(0.8)$ years (median 9.5, range 5-13 years); and the age of those with inactive coeliac disease was $9(0 \cdot 8)$ years (median 8 , range 2.5-19 years). There was no significant difference between the three groups.

ENZYME LINKED IMMUNOSORBENT ASSAY (ELISA) PROCEDURE FOR PLACENTAL FERRITIN

Serum placental ferritin concentrations were determined by a previously described ELISA method. ${ }^{710}$ The assay uses two monoclonal antibodies (CM-G-8) and CM-H-9) developed by one of us (CM). Monoclonal antibody CM-G-8 binds to all isoferritins, whereas $\mathrm{CM}-\mathrm{H}-9$ binds to placental ferritin only. In brief, CM-G-8 was 
coupled to the solid phase, and test sera were added to the wells. After incubation and washing, alkaline phosphatase conjugated CM-H-9 was added to each well. Colour was developed by the addition of p-nitrophenylphosphate substrate, and read in an ELISA reader at $405 \mathrm{~nm}$. The amount of placental ferritin that bound $250 \mathrm{pg}$ of alkaline phosphatase conjugated $\mathrm{CM}-\mathrm{H}-9$ was arbitrarily considered to be $10 \mathrm{U}$ of placental ferritin, and the results were expressed as $\mathrm{U} / \mathrm{ml}$.

\section{ISOLATION OF LYMPHOCYTES}

Peripheral blood lymphocytes were isolated from fresh heparinised blood of five patients with active coeliac disease and high serum levels of placental ferritin by Ficoll-Hypaque gradient density centrifugation.

IMMUNOFLUORESCENCE STAINING OF PLACENTAL FERRITIN ON PERIPHERAL BLOOD LYMPHOCYTES

\section{Membrane staining}

Lymphocytes were washed twice at room temperature with phosphate buffered saline (PBS) containing $2 \%$ bovine serum albumin (BSA) and $0.01 \%$ sodium azide (BSA-PBS). Two aliquots containing $1 \times 10^{6}$ cells each were incu-

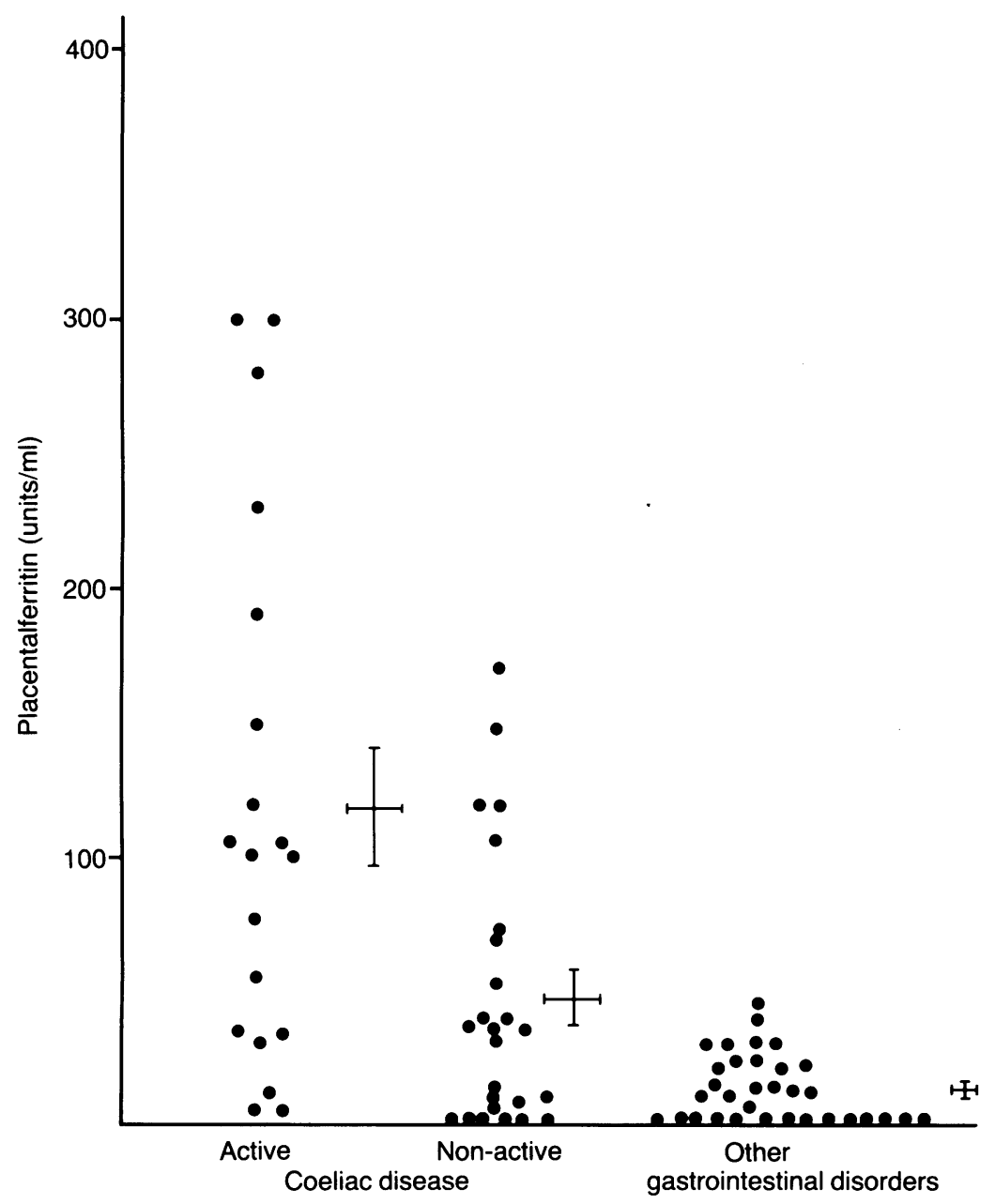

Figure 1: Serum placental ferritin values in 19 children with active and 25 with inactive coeliac disease, and in 32 control subjects. Bars and vertical lines represent the mean (SEM). $p<0.00001$ (active coeliac v controls); $p<0.006$ (active $\mathrm{v}$ inactive coeliac disease); and $p<0.03$ (inactive coeliac $\mathrm{v}$ controls). bated with $25 \mu$ l of diluted monoclonal antibody CM-H-9 overnight at $4^{\circ} \mathrm{C}$. After three washes in BSA-PBS, the cells were incubated with $25 \mu \mathrm{l}$ fluorescein conjugated rabbit anti-mouse immunoglobulin (Dakopatts, Denmark) for 30 minutes at room temperature. After three washes and centrifugation, the cell pellets were suspended in $20 \mu \mathrm{l}$ of BSA-PBS and examined with a fluorescence microscope, with an excitation wave length of $288 \mathrm{~nm}$.

\section{Cytoplasmic staining}

Lymphocytes $\left(1 \times 10^{6}\right)$ were centrifuged onto precleaned microscope slides (Cytospin, Shandon Scientific), air dried for five minutes, and fixed in absolute methanol for 10 minutes at $-15^{\circ} \mathrm{C}$. Cells were washed once in PBS for five minutes and incubated with $100 \mu \mathrm{l}$ of monoclonal antibody CM-H- 9 overnight at $4^{\circ} \mathrm{C}$. After three washes in PBS (five minutes each) the cells were further incubated for 30 minutes at room temperature with a $1 \mathrm{mg} / \mathrm{ml}$ solution of fluorescent anti-mouse IgG (Dakopatts, Denmark). The cells were washed three times with PBS and examined for cytoplasmic fluorescence.

\section{IMMUNE STAINING OF INTESTINAL BIOPSY} SPECIMENS AND LYMPHOMA

Formalin fixed, paraffin embedded intestinal biopsy specimens from five patients with active coeliac disease, five with coeliac disease in remission, five with failure to thrive, and three with active Crohn's disease were used. All biopsy specimens had been taken for the normal investigation of the patients and not for the purposes of the present study. Immune staining was done on an unused portion of specimen kept in our pathology department. Slides from two cases of adult onset enteropathy associated $T$ cell lymphoma were kindly supplied by $\mathrm{Dr} J$ Spencer, Department of Histopathology, The Middlesex Hospital, London.

The slides were deparaffinised by warming for 30 minutes at $60^{\circ} \mathrm{C}$ and xylol washing for 10 minutes, rehydrated by sequential immersion in absolute and $95 \%$ alcohol for five minutes each, and then washed for 10 minutes in distilled water. The slides were then trypsinised for 10 minutes in a $0.1 \%$ trypsin solution (Sigma, Israel) at $37^{\circ} \mathrm{C}$. Endogenous peroxidase was blocked by immersion for 30 minutes in a solution of $0.3 \%$ hydrogen peroxide in absolute methanol. Non-specific binding sites were blocked by incubation for 30 minutes at room temperature with a $20 \%$ solution of normal rabbit serum (Dakopatts, Denmark) in PBS. After washing, the tissue slides were incubated overnight at $4^{\circ} \mathrm{C}$ with a solution of monoclonal antibody CM-H-9 $(1 \mathrm{mg} / \mathrm{ml})$ diluted 1:20 with $1 \% \mathrm{BSA}$ in PBS. After washing, the slides were incubated for 40 minutes at room temperature with a $20 \%$ solution of peroxidase conjugated rabbit anti-mouse antibody $(1 \mathrm{mg} / \mathrm{ml}$, Dakopatts, Denmark) in PBS. After a final wash, the slides were incubated at room temperature for 15 minutes in the dark with a solution containing $0.5 \mathrm{mg} / \mathrm{ml}$ of the substrate $3,3^{\prime}-$ diaminobenzidine (Sigma, Israel) and 0.03\% 


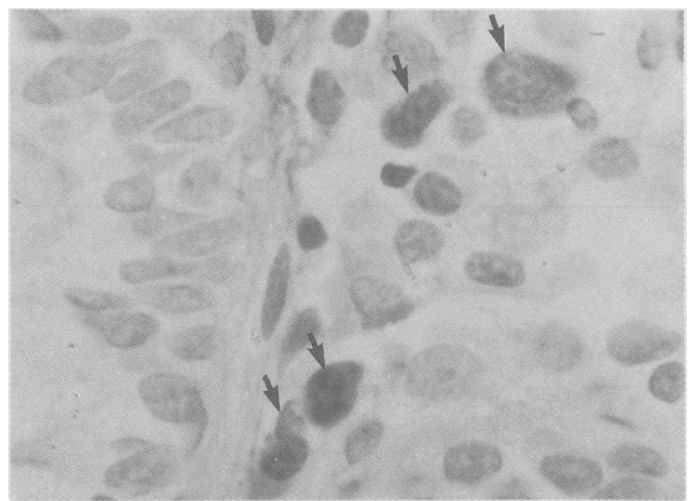

Figure 2: Placental ferritin containing lymphocytes in lamina propria of a patient with active coeliac disease (arrows). (Original magnification $\times 400$.)

hydrogen peroxide in PBS. The slides were then washed and counterstained with haematoxylin. Control sections were incubated with normal rabbit serum instead of CM-H-9.

\section{STATISTICAL ANALYSIS}

This was performed using the Mann-Whitney $U$ test (non-parametric).

\section{Results}

The results of serum placental ferritin concentrations are shown in Figure 1. The mean (SEM) control value was $12.6(2.4)$ while those of the patients with active and inactive coeliac disease were $117(22 \cdot 8)$ and $43.8(10 \cdot 2) \mathrm{U} / \mathrm{ml}$, respectively.

Children with active coeliac disease differed significantly from both control subjects $(\mathrm{p}<0.00001)$ and those with inactive disease $(\mathrm{p}<0.006)$. Controls and children with inactive disease also differed significantly $(\mathrm{p}<0.03)$. Only eight of the 25 children with inactive coeliac disease had a serum placental ferritin value above the upper limit of normal, which is $40 \mathrm{U} / \mathrm{ml}$, while concentrations were increased in most of the children with active coeliac disease (13 of 19 children).

Four patients with active coeliac disease were studied longitudinally. Placental ferritin values decreased after eight to 18 months on a gluten free diet (data not shown).

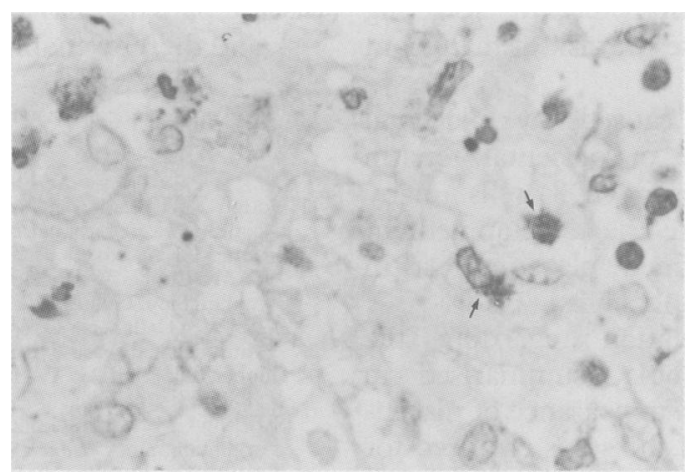

Figure 3: Placental ferritin positive, well differentiated malignant cells in a patient with adult onset enteropathy associated T cell lymphoma (arrows). (Original magnification $\times 400$.)
Staining peripheral blood lymphocytes failed to show placental ferritin, either in the cytoplasm or on the cell membranes.

Immune staining of intestinal biopsy specimens from children with active coeliac disease showed that approximately $40-50 \%$ of the lamina propria lymphocytes were positive for placental ferritin (Fig 2). Very few intraepithelial lymphocytes were found to contain placental ferritin, and epithelial intestinal cells were always negative for this. Nor did biopsy specimens from control subjects, children with inactive coeliac disease, or Crohn's disease contain placental ferritin bearing lymphocytes.

About $20 \%$ of the smaller, better differentiated malignant cells in biopsy specimens of enteropathy associated lymphoma from two adult patients stained positively for placental ferritin (Fig 3).

\section{Discussion}

The lymphomas associated with coeliac disease are mostly non-Hodgkin's lymphoma, and about $80 \%$ are intestinal. ${ }^{4511}$ Most $(85-90 \%)$ of the intestinal lymphomas are of one histological type, classified in the older reports as reticulum cell sarcoma, ${ }^{1}$ and later as histiocytic lymphoma. ${ }^{5}$ Isaacson et al ${ }^{12}$ suggested that most lymphomas associated with coeliac disease were cases of malignant histiocytosis. Recent studies strongly suggest that the lymphoma is a $\mathrm{T}$ cell one. ${ }^{41314}$

Moroz et $a l^{7}$ found increased placental ferritin concentrations in the sera of patients with Hodgkin's and non-Hodgkin's lymphoma of low and intermediate grades. During remission, placental ferritin values fall to a value similar to that of healthy subjects. None, or very low values were found in the sera of patients with multiple myeloma or chronic lymphatic leukaemia. It was thought that the placental ferritin originated in the malignant cells, although this was not shown directly.

In addition to lymphoma, placental ferritin is increased in premalignant and early stage breast cancer, ${ }^{15}$ in patients with AIDS related complex, ${ }^{16}$ and is normally found in the serum of pregnant women. ${ }^{10}$

Our results show that in the absence of lymphoma, patients with active coeliac disease have high values of placental ferritin, an antigen associated with lymphoma, while low or negative concentrations are seen in most patients on a gluten free diet. It usually takes at least several months before a decline is seen. It is possible that constantly high placental ferritin values despite gluten free diet were caused by conscious or inadvertent gluten ingestion. As we do not have biopsy tissue from these patients during this stage, this possibility cannot be either proved or discounted.

The absence of placental ferritin bearing peripheral blood lymphocytes, the presence of placental ferritin positive cells in the intestinal lamina propria in active coeliac disease, and the absence of placental ferritin containing cells in intestinal biopsy tissue from controls, children with Crohn's disease, or those with inactive coeliac disease, suggest that the serum placental 


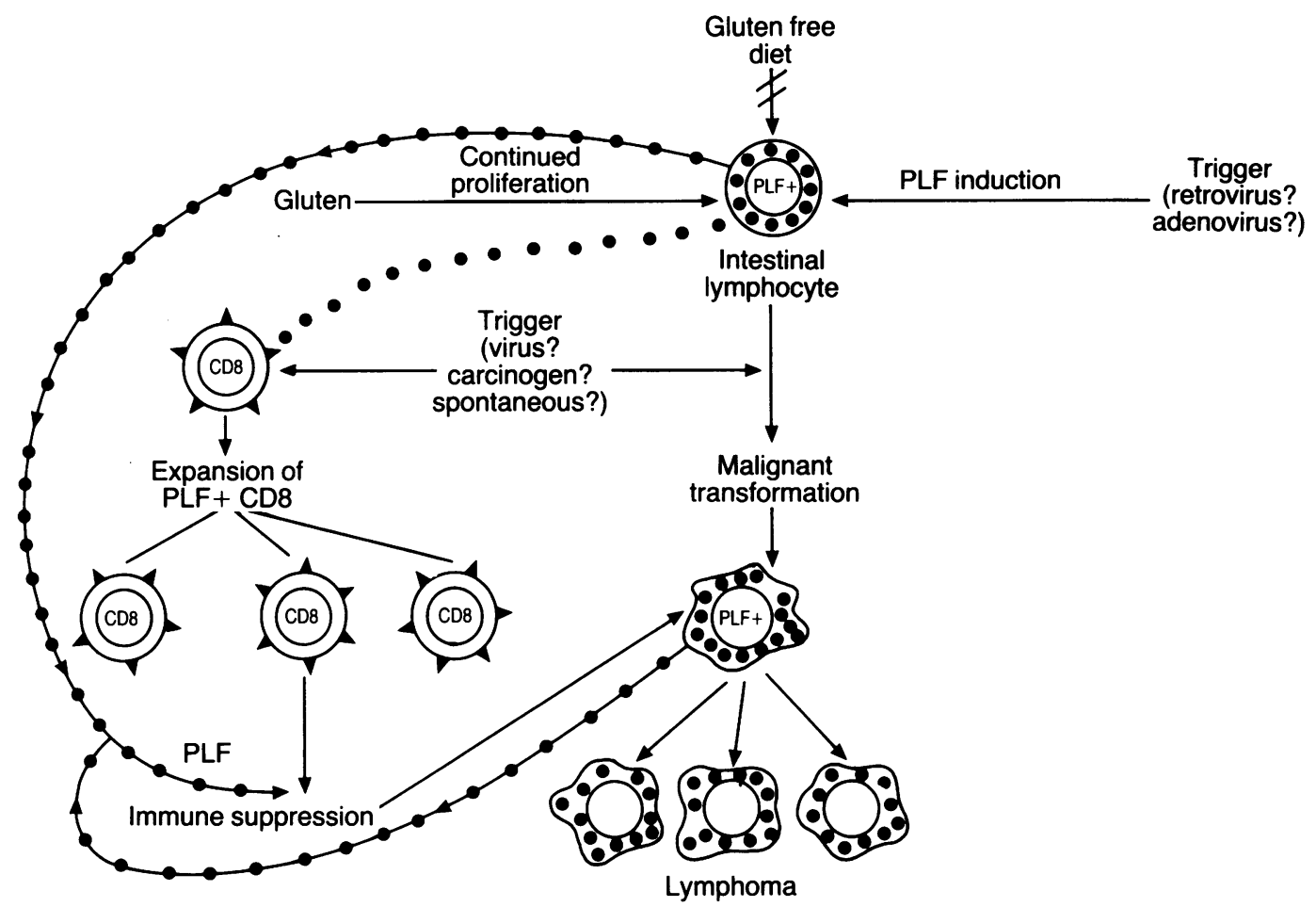

Figure 4: Hypothesis on the possible role of placental ferritin $(P L F)$ in the development of lymphoma in coeliac disease. An unknown trigger induces $P L F$ production in some intestinal lymphocytes. Gluten enhances, and gluten free diet inhibits, continuing proliferation of these lymphocytes. Other triggers may cause malignant transformation of $P L F$ producing lamina propria lymphocytes, and production of $P L F$ receptor bearing $C D 8$ cells. In the presence of $P L F$, immunosuppression is produced, which may allow expansion of the malignant cell population and production of lymphoma.

ferritin originates in lamina propria lymphocytes.

It is now generally accepted that there are two distinct populations of lymphoid cells residing in the gut mucosa - those in the lamina propria and the intraepithelial lymphocytes. The former are mostly of the helper phenotype, while the latter are predominantly cytotoxic-suppressor. ${ }^{17} \mathrm{We}$ were not able to characterise directly the intestinal placental ferritin positive cells in our patients, but the fact that most are in the lamina propria and not intraepithelial lymphocytes, suggests that they are of the helper (CD4) phenotype. This is consistent with the findings in early HIV infection, where placental ferritin is thought to originate in CD4 lymphocytes. ${ }^{16}$

In coeliac disease, the secretion of placental ferritin may be activated by some trigger (such as adenovirus, which contains a protein similar to an amino acid sequence of $\alpha$ gliadin), ${ }^{18}$ and maintained by gluten. Continuous proliferation of the intestinal placental ferritin secreting lymphocytes may increase the risk of malignant transformation.

Immunosuppression, caused by placental ferritin in the presence of placental ferritin receptor bearing suppressor (CD8) cells ${ }^{19}$ or by $\alpha$ gliadin, ${ }^{20}$ may facilitate the development of lymphoma from transformed, placental ferritin producing, intestinal lymphocytes.

If the above speculation regarding the development of lymphoma, summarised in Figure 4, is true, then the appearance of placental ferritin may be one of the steps required for the development of malignancy. A gluten free diet, by inhibiting its production, may prevent lymphoma development. The presence of placental ferritin positive cells in the slides from the patients with adult onset enteropathy associated $\mathrm{T}$ cell lymphoma lends further support to our hypothesis. Only smaller, well differentiated malignant cells were found to be placental ferritin positive. This is consistent with previous observations in non-Hodgkin's lymphoma, where the highest placental ferritin values were found in sera from patients with low grade lymphoma, which represents the most differentiated tumour cells.?

It is not known if strict adherence to gluten free diet in childhood will reduce the risk of developing lymphoma in patients with coeliac disease. Nevertheless, preliminary results suggest that gluten free diet may indeed have a role in the prevention of malignancy. ${ }^{21-23}$

Patients on a gluten free diet in whom placental ferritin does not decrease may prove to be in a higher risk category for the development of malignancy, when other factors are controlled. Monitoring placental ferritin values in coeliac disease patients may help identify those at high risk and thereby enable early diagnosis.

The excellent technical assistance of Bilha Zingerman is gratefully acknowledged.

1 Gough KR, Read AE, Naish JM. Intestinal reticulosis as a complication of idiopathic steatorrhea. Gut 1962; 3: 232-9.

2 complication of idiopathic steatorrhea. Gut 1962; 3: 232-9. JAM, Cooke WT. Coeliac disease, gluten free diet and JAM, Cooke WT. Coeliac dise
malignancy. Gut 1976; 17:612-9.

malignancy. Gut 1976; 17: 612-9.
Selby WS, Gallaher ND. Malignancy in a 19 year experience of adult celiac disease. Dig Dis Sci 1979; 24: 684-7.

4 Cooper BT, Read AE. Coeliac disease and lymphoma. $Q \mathcal{O F}$ Med 1987; 63: 269-74.

5 Swinson CM, Slavin G, Cotes FC, Booth CC. Coeliac disease and malignancy. Lancet 1983; i: 111-5.

6 Keating JP. Is celiac disease a premalignant state? $\mathcal{F}$ Pedia Gastroenterol Nutr 1984; 3: 4-5.

7 Moroz C, Bessler H, Lurie Y, Shaklai M. New monoclonal antibody enzymoassay for the specific measurement of placental ferritin isotype in hematologic malignancies. $E x p$ Hematol 1987; 15: 258-62. 
8 Moroz C, Marcus H, Zahavi I, Dinari G. Is coeliac disease a premalignant state? Lancet 1988; ii: 903-4.

9 Meeuwisse GW. Diagnostic criteria in coeliac disease. Acta Paediatr Scand 1970; 59: 461-3.

10 Moroz C, Bessler H, Sirota L, Dulitzky F, Djaldetti M. Difference in the placental ferritin levels measured by a specific monoclonal antibody enzymoassay in preterm and term delivery. Clin Exp Immunol 1987; 69: 702-6.

11 Cooper BT, Holmes GKJ, Ferguson R, Cooke WT. Celiac Cooper BT, Holmes GKJ, Ferguson R, Cooke WT
disease and malignancy. Medicine 1980; 59: 249-61.

12 Isaacson P, Wright DH. Intestinal lymphoma associated with malabsorption. Lancet 1978; i: 67-70.

13 Loughran TP, Kolin ME, Deeg HJ. T-cell intestinal lymphoma associated with celiac sprue. Ann Intern Med 1986; 104: $44-7$.

14 Salter DM, Krajewski AS, Dewar AE. Immunophenotype analysis of malignant histiocytosis of the intestine. $\mathcal{F}$ Clin Pathol 1986; 39: 8-15.

15 Moroz C, Kan M, Chaimoff C, Marcus H, Kupfer B, Cuckle $\mathrm{S}$. Ferritin bearing lymphocytes in the diagnosis of breast cancer. Cancer 1984; 54: 84-9.

16 Moroz C, Misrock SL, Siegal FPS. Isoferritin in HIV infections: relation to clinical stage, CD8 lymphocyte binding tions: relation to clinical stage, CD8 lymphocyte
and the pathogenesis of AIDS. AIDS 1989; 3: 11-6.
17 Lyscom N, Brueton MJ. Intraepithelial, lamina propria and Peyer's patch lymphocytes of the rat small intestine: isolation and characterization in terms of immunoglobulin markers and receptors for monoclonal antibodies. Immunology 1982; 45: 775-83.

18 Kagnoff MF, Paterson YJ, Kumar PJ, Kasarda DD, Carbone FR, Unsworth DJ, et al. Evidence for the role of a human intestinal adenovirus in the pathogenesis of coeliac disease. Gut 1987; 28: 995-1001.

19 Matzner Y, Konijin AM, Shlomai Z, Ben-Basat H. Differential effect of isolated placental isoferritin on in-vitro $T$ lymphocyte function. Br $\mathcal{H}$ Haematol 1985; 59: 443-8.

20 O'Farrelly C, Whelan CA, Feighery CF, Weir DG Suppressor-cell activity in coeliac disease induced by alphagliadin, a dietary antigen. Lancet 1984; ii: 1305-7.

21 McNicholl B. Coeliac disease: ecology, life history and management. Hum Nutr Appl Nutr 1986; 40A (suppl 1): $55-9$.

22 Anonymous. Growing up with coeliac disease [Editorial]. Lancet 1988; ii: 1231-2.

23 Holmes GKT, Prior P, Lane MR, Pope D, Allan RN. Malignancy in coeliac disease - effect of a gluten-free diet. Gut 1989; 30: 333-8. 